\title{
Why rheumatologic skin disease?
}

Some might ask, "Why devote publication space to such a narrow subject as rheumatologic (syn. rheumatic) skin disease in a reputable, broadly-based scientific journal such as the Annals of Translational Medicine that covers thought and translational investigation concerning all diseases that can affect the human body?"

Rheumatologic disorders (syn. rheumatism) are medical conditions that cause chronic, intermittent pain resulting from dysfunction of joints and connective tissue. There are approximately 200 different classifiable rheumatologic disorders. Some are quite rare (e.g., idiopathic inflammatory myopathies) while others are very common [osteoarthritis (degenerative joint disease)]. When taken together rheumatologic disorders account for a considerable quality-of-life and economic burden throughout the world.

Arthritis is the leading cause of disability in the United States. The Centers for Disease Control and Prevention reported that the total cost of arthritis and other rheumatologic conditions in the United States was approximately \$128 billion in the year 2003. This was equivalent to $1.2 \%$ of the 2003 U.S. gross domestic product (1). With the aging population, that annual cost was projected to grow considerably.

Chronic, disfiguring and difficult-to-treat skin changes of some rheumatologic disorders can produce profound impacts on a person's life. In addition to economic costs, rheumatologic skin disorders can be profoundly debilitating. Healthcare quality-of-life studies have repeatedly shown that the life-impact of chronic skin disease is similar to that of chronic vital internal organ diseases including cardiovascular disease, renal disease and neurologic disease.

Rheumatologic disorders can be divided into three broad functional categories-degenerative, autoinflammatory and autoimmune. The subject of this Series will be on the cutaneous manifestations of the autoimmune connective tissue diseases including lupus erythematosus (LE), dermatomyositis (a member of the idiopathic inflammatory myopathies), morphea and systemic sclerosis (i.e., autoimmune scleroderma) and vasculitis. These are genetically-complex, heterogeneously-expressed autoimmune clinical disorders that can impact both vital internal organ systems as well as the skin. The manner in which the skin is affected clinically can provide insight into the prognosis for vital internal organ involvement and dysfunction. The impact of environmental influences on the genetically-susceptible rheumatologic disease host deserve further exploration.

The skin is among the most accessible organ systems in the human body for studying autoimmune clinical phenomena. As a visible organ, it allows a level of observational nuance not afforded by other organ systems. Careful observation in skin provides an ability for defining naturally occurring biologic subgroups that have the potential to reveal novel genetic/ immunologic/molecular correlations that have important ramifications for understanding disease pathophysiology.

Both lesional and non-lesional skin biopsies can be readily obtained for translational clinical research studies. Experimental pathologic studies of LE skin lesion tissue were critical in documenting that interferon gene dysregulation is a biomarker for immunologic tissue injury in the early inflammatory stages of LE, dermatomyositis and morphea/systemic sclerosis. Much is being learned in the context of translational and interventional studies about disease heterogeneity and the role of specific, potentially-targetable pathways. This understanding has led to completely new targeted treatment strategies for these and related clinical disorders.

When considering human organ systems, the vasculature has typically been listed as a component of the circulatory system along with the heart and circulating blood cells. However, early observations into the pathogenesis of extrapulmonary tissue injury in patients with severe Covid-19 illness have suggested that the microvascular endothelium is the initial target for viral injury of vital internal organs such as the heart, kidneys, liver and brain.

As such, some have felt that the human vasculature might better be viewed as an organ system unto itself. This could focus more research interest and research funding on clinical disorders that result primarily from human vasculature injury such as vasculitis. Research progress on cutaneous vasculitis has been quite sluggish in the past. However, international research collaborations such as the Diagnostic and Classification Criteria in Vasculitis (DCVAS) Study promise to facilitate progress in this area.

In the past, progress has been slow in identifying new treatment options for the cutaneous manifestations of the autoimmune connective tissue diseases. This was in part due to the fact that these are rare/orphan clinical disorders. Being less profitable, they attracted little attention from the pharmaceutical industry. In addition, the lack of validated clinical 
tools for quantifying clinical trial endpoints of cutaneous inflammation and damage also contributed to the lack of progress. The recent development and validation of such clinical tools for classifying degrees of skin disease activity and damage for cutaneous LE and dermatomyositis are leading the way in overcoming this obstacle. The Cutaneous Lupus Erythematosus Disease Area and Severity Index (CLASI) and the Cutaneous Dermatomyositis Disease Area and Severity Index (CDASI) are prime examples of such clinical tools. There have been no new approved medications for these diseases in over 50 years, and ongoing and future studies have the potential to significantly advance therapeutic options in the near future.

Patient-oriented translational clinical research is a circular process. It begins and ends at the bedside and in the clinic. Clinical observation leads to clinical belief and hypothesis generation which are the forces that drive the patient-oriented translational clinical research engine. Changes in the skin are among the most easily observable of clinical phenomena. And, disordered function of the skin can be a window into disordered function of vital internal organs. In addition, skin disease tissue can be readily-obtained for research purposes. The content of the narrative reviews in this Series was designed to provide non-dermatologist readers with a better perspective on the value of clinical observation and translational research focused on the cutaneous manifestations of genetically-complex, environmentally-impacted and variably-expressed human illnesses such as the autoimmune connective tissue diseases.

\section{Acknowledgments}

The authors of this editorial would like to express their sincere appreciation to the authors of the various narrative review manuscripts in this Series. The Covid-19 pandemic burst upon the manuscript authors during the time frame that they had been allotted for composing and submitting their manuscripts. We feel certain that this extraordinary distraction presented substantial challenges to the manuscript authors in meeting their writing and submission deadline commitments. We thank them for finding ways to overcome this considerable challenge.

Funding: None.

\section{Footnote}

Provenance and Peer Review: This article was commissioned by the editorial office, Annals of Translational Medicine for the series "Rheumatologic Skin Disease." The article did not undergo external peer review.

Conflicts of Interest: All authors have completed the ICMJE uniform disclosure form (available at http://dx.doi.org/10.21037/ atm-2020-rsd-14). The series "Rheumatologic Skin Disease" was commissioned by the editorial office without any funding or sponsorship. All four authors served as the unpaid Guest Editors of the series. Dr. Werth reports that she has a patent CLASI licensed. The authors have no other conflicts of interest to declare.

Ethical Statement: The authors are accountable for all aspects of the work in ensuring that questions related to the accuracy or integrity of any part of the work are appropriately investigated and resolved.

Open Access Statement: This is an Open Access article distributed in accordance with the Creative Commons AttributionNonCommercial-NoDerivs 4.0 International License (CC BY-NC-ND 4.0), which permits the non-commercial replication and distribution of the article with the strict proviso that no changes or edits are made and the original work is properly cited (including links to both the formal publication through the relevant DOI and the license). See: https://creativecommons.org/licenses/by-nc$\mathrm{nd} / 4.0 \%$.

\section{References}

1. Centers for Disease Control and Prevention (CDC). National and state medical expenditures and lost earnings attributable to arthritis and other rheumatic conditions--United States, 2003. MMWR Morb Mortal Wkly Rep 2007;56:4-7. 


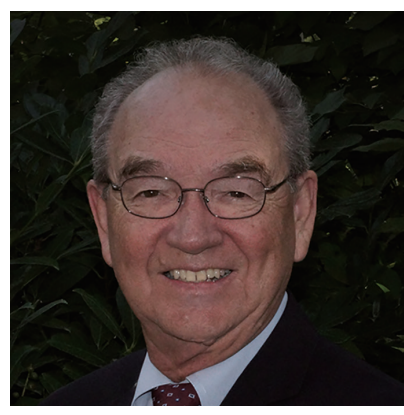

Richard D. Sontheimer

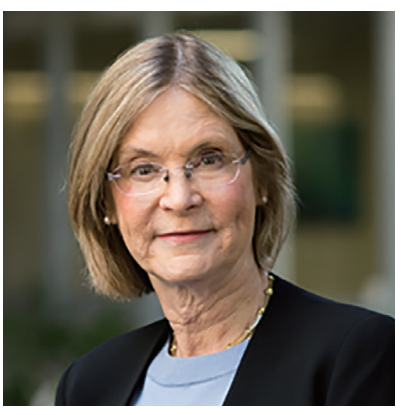

M. Kari Connolly

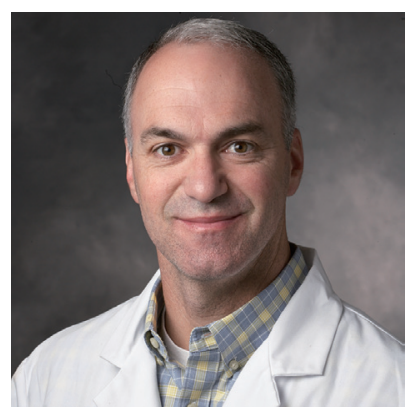

David F. Fiorentino

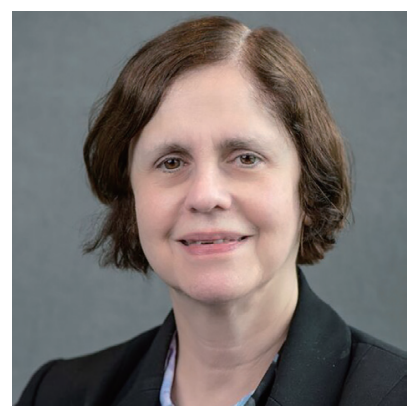

Victoria P. Werth

Richard D. Sontheimer, MD

Department of Dermatology, University of Utah School of Medicine, Salt Lake City, Utah, USA.

(Email: richard.sontheimer@hsc.utah.edu)

M. Kari Connolly, MD

Department of Dermatology, University of California at San Francisco School of Medicine, San Francisco, California, USA.

(Email: Connolly@derm.ucsf.edu)

David F. Fiorentino, MD

Department of Dermatology, Stanford University School of Medicine, Palo Alto, California, USA.

(Email: fiorentino@stanford.edu)

Victoria P. Werth, MD

Department of Dermatology, University of Pennsylvania School of Medicine, Philadelphia, Pennsylvania, USA.

(Email:werth@mail.med.upenn.edu)

Submitted Oct 20, 2020. Accepted for publication Dec 18, 2020.

doi: 10.21037/atm-2020-rsd-14

View this article at: http://dx.doi.org/10.21037/atm-2020-rsd-14

Cite this article as: Sontheimer RD, Connolly MK, Fiorentino DF, Werth VP. Why rheumatologic skin disease? Ann Transl Med 2021;9(5):428. doi: 10.21037/atm-2020-rsd-14 